Article

\title{
Resource Use and Deprivation: Geographical Analysis of the Ecological Footprint and Townsend Index for England
}

\section{Stephen Morse ${ }^{1}$ and Ioannis N. Vogiatzakis ${ }^{2, *}$}

1 Centre for Environmental Strategy, University of Surrey, Guildford, Surrey GU2 7XH, UK; E-Mail: S.Morse@surrey.ac.uk

2 School of Pure and Applied Sciences, Open University of Cyprus, PO Box 12794, Nicosia 2252, Cyprus

* Author to whom correspondence should be addressed; E-Mail: ioannis.vogiatzakis@ouc.ac.cy; Tel.: +357-2241-1933.

Received: 18 May 2014; in revised form: 21 July 2014 / Accepted: 22 July 2014 /

Published: 28 July 2014

\begin{abstract}
The relationship between consumption and deprivation has been explored at various scales in the literature. It would be expected that increased deprivation leads to less consumption and vice versa. However, what is the form of that relationship? Evidence from international studies using the Human Development Index (HDI) and Ecological Footprint (EF) for nation states suggest that the relationship is curved such that an increase in HDI (decrease in deprivation) is linearly associated with an increase in EF (consumption and impact on the environment) up to a point but beyond that there can be widely different values for the EF for the same value of HDI. Given that deprivation and consumption within a single country can be expected to be more homogenous than that observed between countries does this result in a linear relationship between the two variables? We tested the relationship between the Townsend Index of Deprivation (TID) and EF for English regions, using fine scale data as derived from the UK Census and the Stockholm Environment Institute respectively. The results suggest that the relationship between the EF and deprivation for most English regions is markedly linear; with the level of deprivation declining with increasing EF. The picture is remarkably consistent across most of the regions and the only region where this simple picture becomes distorted is London. The paper discusses the relevance of this finding and implications for future research.
\end{abstract}


Keywords: Ecological Footprint; Townsend Index of Deprivation; Human Development Index; England

\section{Introduction}

Sustainable development has long been articulated as having three overlapping concerns of the environment, community and economics. The overlap is important as it implies that any one of these concerns should not dominate any of the others. Thus, economic growth should not take place to the detriment of the environment and/or society as a whole, and indeed some have argued that economic growth is not necessary or indeed desirable in sustainable development [1]. While the relationship between economic growth and sustainable development has been hotly debated, it is certainly the case that economic growth is sought after by a large percentage of the population of any one country, not least the UK, and this has been especially apparent since the downturn in the economy as of 2008. Figure 1 shows the real GDP figures (chained to 2005) for the UK up until 2011, and the downturn for 2008 was marked even in comparison to the downturns of two World Wars and the slump in the 1930s. The use of 'real' GDP where the value of the currency is pegged to a specific year (in this case 2005) removes the effect of inflation. Thus, the temptation for politicians may be to get the economy moving almost at any cost, even if it means a negative impact on the environment or indeed parts of society.

Figure 1. Percentage change in Gross Domestic Product (GDP for the UK economy between 1900 and 2011. GDP has been "chained" to 2005.

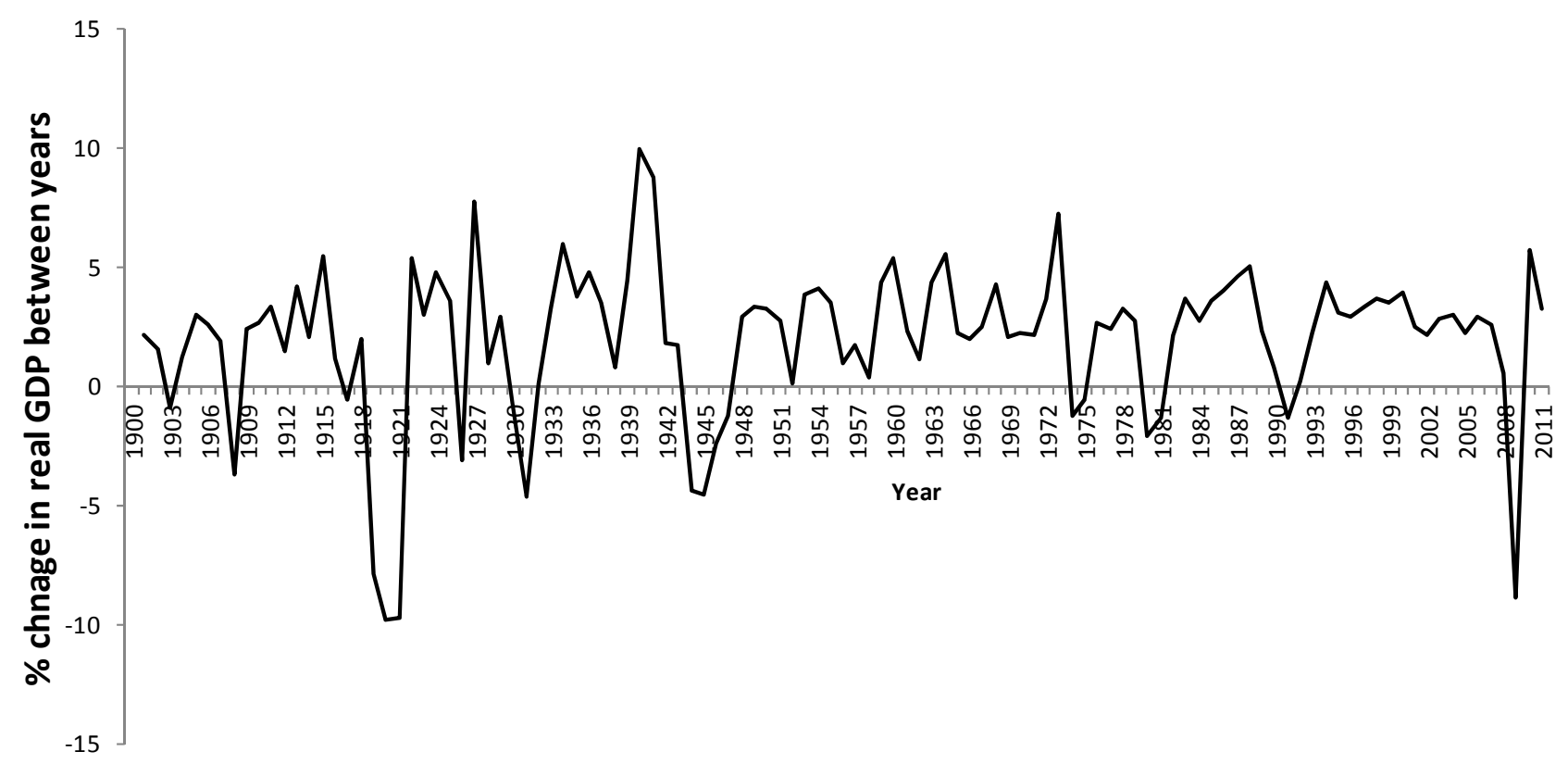

This "trade off" between the components of SD is not new, and is being played out on a daily basis across all countries of the globe. While various "national scale" measures exist for economic growth, and one of them (GDP) has been used for Figure 1, measuring impact on the environment and society at the same scale is not so straightforward. One important issue is that such impacts can be very different across spaces within a single country and indeed within communities living in the same place. 
This paper will explore some of the relationships that exist between regions of the same country in terms of some of the key considerations within SD; most notably consumption and social deprivation. The use of resource consumption by a population has certain advantages in that it can accommodate impacts that are not necessarily local to that consumption; for example the import of goods from foreign countries. There are well-established tools such as the Ecological Footprint (EF) which allow for such assessment. The EF is primarily an index of consumption and attempts to present that dimension of human behavior in terms of the land area (or more accurately-equivalent bioproductive land area) required to support it [2-8]. The EF can be calculated for any size of population from an individual through to the global population and to adjust for such differences the EF is typically expressed on a per capita basis. The assumption is that the greater the EF per capita then the higher is the consumption and the worse is the negative impact on the planet, and the use of bioproductive land areas (global hectares; gha) as the unit to express such consumption means that people can readily appreciate the impact that they are having. Larger values for the EF can be associated with a sense of "greed" [9] and the mantra of keeping one's footprint as low as possible is something that can be readily articulated. Thus, the EF becomes a proxy assessment of environmental impact arising from human beings, although as will be seen later in the paper this is not a straightforward assumption. The extent of social deprivation can be thought of as a community impact that goes beyond a focus solely on income per household.

The notion of envisioning consumption in terms of land area has been promoted by various groups who calculate their own version of the EF. The "Footprint for Nations" version of the EF is published by Global Footprint Network [10] and appears as one of two key indices in the World Wildlife Funds "Living Planet Reports" [11]. The "Living Plant Reports" which contain values of the EF for nation-states have been published every two years since 2000; the two reports published before 2000 did not have the EF. The linkage between national EF, as determined by bodies such as the Global Footprint Network, and "quality of life", as embodied by the Human Development Index (HDI) of the UNDP, have been explored in the literature [12]. The HDI was initially developed as a means of measuring the extent of "human development" at the scale of the nation state. The HDI comprises three elements, namely income/capita, education and life expectancy, and ranges between 0 and 1; with higher values equating to "more" development. For many years the HDI was a simple arithmetic average of these three components, and higher values of the HDI (up to a maximum of 1) equate to "better" human development (or less deprivation). Lower values of the HDI equate to less human development, or, put another way, increasing deprivation. However, this is seeing human development (or deprivation as the mirror image) in very limited terms as comprising just three components. The decision to include a small number of components was purposely made by the UNDP as they wished to keep it as simple and as transparent as possible [12]. Strictly speaking, the HDI was not intended to be a measure of "quality of life" but is often reported in the media using such terms. A number of studies have shown that the relationship is linear over the lower range of EF and HDI, but HDI begins to level off at higher values of the EF [12]. A graphical example of the relationship between EF and the HDI for countries is presented as Figure 2. This can, of course, also be articulated in terms of deprivation rather than "quality of life" (development), where the former is seen as the inverse of the latter. In Figure 3 this has simply been achieved by subtracting the HDI from 1 (higher values equate to greater deprivation). Thus, in effect, more EF (seen in terms of consumption) does not necessarily generate more 
development/less deprivation; there is a diminishing return. In effect the relationship between EF and deprivation begins with a sharp decline in deprivation as EF increases, but this becomes shallower and eventually levels off completely.

Figure 2. Relationship between Ecological Footprint (EF; Global Footprint Network) and Human Development Index (HDI). Each point in the graph is for a single country.

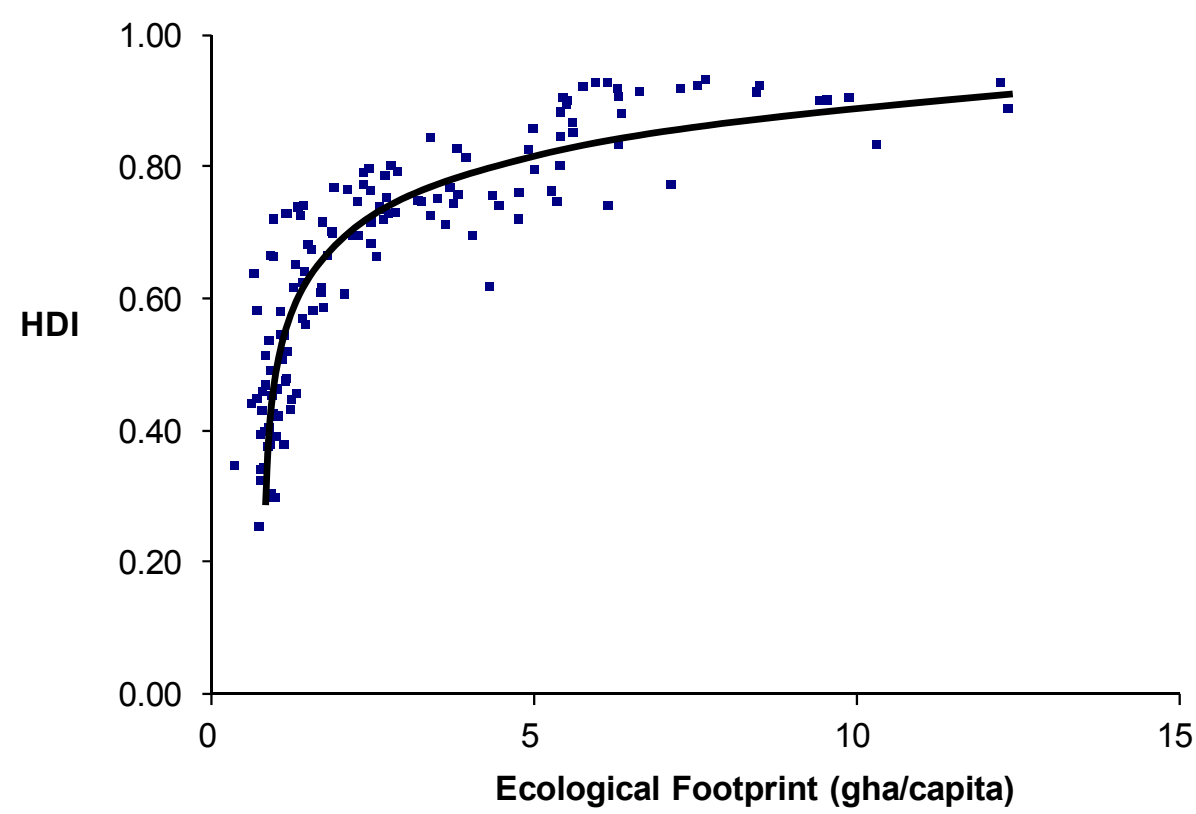

Figure 3. Relationship between Ecological Footprint (EF; Global Footprint Network) and deprivation (measured as 1-HDI). Each point in the graph is for a single country.

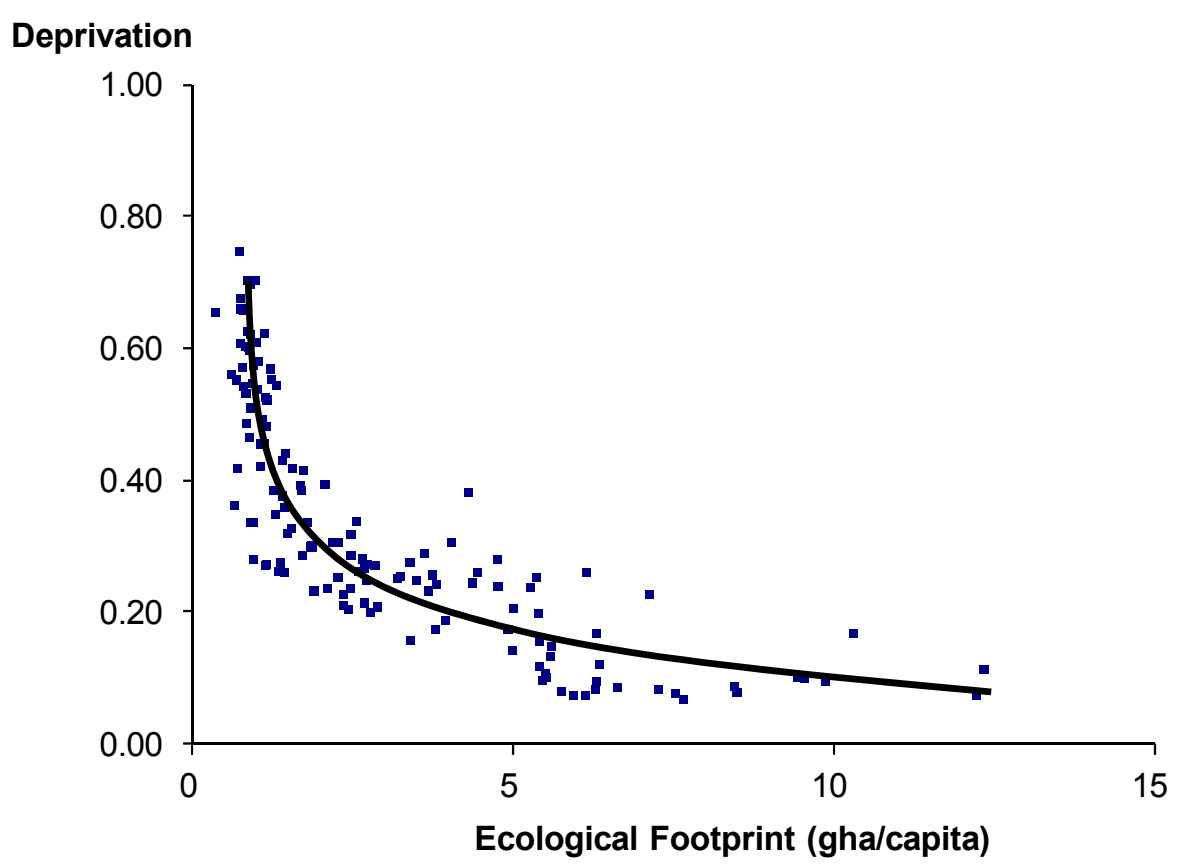

However, the cause-effect relationship seen in Figures 2 and 3 is not straightforward for a number of reasons. Firstly, it has to be reiterated that the HDI is a rather simple index having just three components, even if they are important, and thus is inevitably limited in its ability to capture the 
complexity of "human development". Much the same can be said of the EF, of course, and indeed this measure is also not without its critics. Secondly, EF can be a function of development rather than development being a function of EF (as implied in Figures 2 and 3). Thirdly the dataset for Figures 2 and 3 span a very wide range of EF and HDI values although it should be noted that the HDI is adjusted in such a way as to avoid a dominance of the income/capita component given that this has such a wide disparity between countries. The other two components of the HDI (education and life expectancy) have nothing like the extent of difference seen with the income/capita component largely because they have natural ceilings; the education component cannot be greater than $100 \%$ of children in school and maximum human life expectancy currently tends to be a decade or so after 100. Thus, given that the components of the HDI are effectively "capped" (either naturally or by the use of a mathematical device) then some of the leveling seen in Figure 2 could be an artifact; a point that has not been made in previous studies of the relationship between these two variables.

Perhaps surprisingly there have been far fewer explorations to see whether the diminishing return relationship of Figures 2 and 3 exist within a single country. This is partly because relatively few countries have regional EF and deprivation data, and those countries that do have such data tend to be found in the more affluent developed world. The EF, in particular, is a measure having many methodologies [4] and while there are many examples of cities and regions estimating their own EF it is less common to have a uniform methodology applied to different regions within a country. While there is, of course, much deprivation in the developed world one may perhaps expect a greater degree of homogeneity in terms of deprivation and EF within such countries as the extremes one sees on the global stage are less likely. Thus, in theory, one may expect to see a relationship between EF and quality of life (or deprivation) that covers the part of the relationship towards the right-hand side of the curves seen in Figures 2 and 3 - the shallow declining line-but is that the case? The objective of this paper is to answer this question by drawing upon EF and deprivation data from England.

The United Kingdom, comprising four countries (England, Northern Ireland, Scotland and Wales), is an example of a nation which does have regional data for EF as well as detailed and extensive data which allows for assessment of the level of deprivation at fine spatial scales. England, the largest of the four countries in the UK in terms population and economy, comprises a number of regions, including Greater London. The other three countries are much smaller in terms of population. The level of deprivation at quite fine spatial scales (equating roughly to parishes) can readily be discerned for England using census data, and these can be aggregated to the scale of regions. Mitchell and Norman [13] explored the link between deprivation and a number of indicators of environmental quality between 1960 and 2007 in England and made a convincing case that the relationship is not as straightforward as may be imagined. Indeed they argue that the greatest decline in environmental quality was often in the most affluent areas. However, as noted above the EF is based on consumption and the impact on the environment is assumed to flow from it and go beyond just the immediate local scale. Thus, EF embodies environmental impacts that can be local, national and international. The Stockholm Environment Institute (SEI) has also estimated values of the EF for local authorities across England. Thus, England provides a context within which the above assumptions regarding the relationship between EF and deprivation can be tested. 


\section{Ecological Footprint and Townsend Index}

There are various versions of the EF in existence and the Global Footprint Network version, which is perhaps the most oft-quoted example, deconstructs consumption into the following six components:

(1) Crop land

(2) Forest land

(3) Fishing grounds

(4) Grazing land

(5) Carbon uptake land

(6) Built-up land (urban areas and dams)

The first four of these are straightforward in the sense that they are all related to food production or the consumption of forest for buildings, furniture and fuel. Carbon uptake land is the area required to absorb the carbon produced by a country. Larger EFs imply a greater degree of consumption of resources but can also be interpreted as implying greater waste and inefficiency in use of resources [14]. Nonetheless higher values for the EF imply a bigger negative impact on the environment. However while the six components of the EF have a clear logic the process for estimating such nation-state EFs is complex and based upon a number of key assumptions that are readily contestable [15-18]. Underlying it all is the need for good quality data, although this is arguably more complex with the EF given the range of its components [19-21]. For example, the crop land component employs average figures for crop yields across the globe yet even for a single crop such as maize this can be highly variable both between and within countries and even here the figures may be "guesstimates" based on incomplete data. The use of average yields enables a "fair" comparison of consumption between nations as the data become normalized into global hectares. If results are not normalized it may look like a person from Somalia has a higher footprint than a person from say Germany, because the yield of maize in Somalia is much lower than that of Germany. However, the quality of yield data available in Somalia may be lower than that in Germany, and it is likely that the distribution in yield will also be greater in Somalia and possibly skewed. As a result of this and other concerns the EF has certainly not been without its critics [22] and improvements have been suggested to enhance its association with environmental impact [23].

But while this may probably be the most quoted version of the EF there are others and the SEI version is one of them. The most recent EF dataset for English regions produced by the SEI is for 2004 (released in 2008) and covers expenditure within 63 household consumption categories and a further 73 categories attributed to government services and public infrastructure. It is based on the REAP methodology which ascribes environmental impact to the purchasing of goods, services and investment (expenditure on capital). There are similarities here with Life Cycle Analysis (LCA) but the REAP approach is claimed by its proponents to be simpler. More details on this approach can be found at www.resource-accounting.org.uk [24]. For the purposes of this paper it is only necessary to highlight the nature of the goods, services and capital investment components and these are summarized in Table 1. 
Table 1. Components of the Ecological Footprint as calculated by the SEI for regions of the UK. The table has been adapted from information available via the REAP v2 Experimental release: 15-10-08. Published by SEI 2008. Available at www.resource-accounting.org.uk [24].

\begin{tabular}{|c|c|}
\hline Component of EF & Consumption examples \\
\hline Housing & $\begin{array}{l}\text { Renting of property by tenants; payment of mortgages; routine maintenance of } \\
\text { dwellings to keep them in good working order; indirect impacts of electricity } \\
\text { generation and fuel distribution; cleaning and maintenance products; domestic } \\
\text { service; burning of gas, coal and other fuels in the home; all capital investment } \\
\text { associated with housing }\end{array}$ \\
\hline Transport & $\begin{array}{l}\text { Purchase of cars, motorbikes and bicycles; purchase of spare parts; purchase } \\
\text { of fuel and lubricants; expenditure on railway, air, water etc. transport; } \\
\text { expenditure of UK residents on activities abroad. Includes transport and } \\
\text { spending on holiday; burning of private vehicle fuel during use; capital } \\
\text { investment associated with transport }\end{array}$ \\
\hline Food & $\begin{array}{l}\text { Conventional and organic (where applicable) versions of the following; } \\
\text { Meat and products (excl. poultry); poultry meat and products; organic poultry meat } \\
\text { and poultry meat products; wild fish and fish products from catch; farmed fish and } \\
\text { fish products; fruit and vegetables; vegetable and animal oils and fats; organic oils } \\
\text { and fats; dairy products; grain mill products; starches and starch products; bread; } \\
\text { rusks and biscuits; pastry goods and cakes; cocoa; chocolate and sugar } \\
\text { confectionery; other food products (incl. sugar); non-alcoholic beverages; } \\
\text { alcoholic beverages; catering services; capital investment associated with food }\end{array}$ \\
\hline Consumer Items & $\begin{array}{l}\text { Tobacco; clothing; footwear; furniture; furnishings; carpets etc.; household } \\
\text { textiles; household appliances; glassware; tableware and household utensils; tools } \\
\text { and equipment for house and garden; medical products, appliances and equipment; } \\
\text { telephone and telefax equipment; audio-visual; photo and information processing } \\
\text { equipment; other major durables for recreation and culture; other recreational } \\
\text { equipment; newspapers, books and stationery; personal care; personal effect; } \\
\text { capital investment for consumables }\end{array}$ \\
\hline Private Services & $\begin{array}{l}\text { Water supply and miscellaneous dwelling services; out-patient services; } \\
\text { hospital services; postal services; telephone and telefax services; recreational } \\
\text { and cultural services; package holidays; education "accommodation services" } \\
\text { social protection; insurance; financial services; other services; capital investment } \\
\text { related to private services }\end{array}$ \\
\hline Public Services & $\begin{array}{l}\text { Services provided centrally and locally (where applicable) for the following: } \\
\text { Education; health and veterinary services; sanitation; social work; recreation; } \\
\text { administration; capital investment for public services }\end{array}$ \\
\hline Capital Investment & $\begin{array}{l}\text { Gross fixed capital formation - the value of a producer's acquisitions, } \\
\text { less disposals, of fixed assets during the accounting period }\end{array}$ \\
\hline Other & $\begin{array}{l}\text { Non residents, non-profit institutions serving households, valuables and } \\
\text { changes in inventories }\end{array}$ \\
\hline
\end{tabular}

Indices of deprivation have existed for some years, and were often created as a means of informing health policy [25]. One widely quoted example is the Townsend Index of Deprivation (TID) [26] comprised of four components: 
(1) Unemployment as a percentage of those aged 16 and over who are economically active

(2) No-car ownership (\% of all households)

(3) No-home ownership (\% of all households)

(4) Household overcrowding.

The four variables are combined (with equal weight) to form an overall score. The higher the TID the more deprived and disadvantaged an area is thought to be. The TID is a convenient measure of deprivation in the UK as it can be populated from census data and has been found to be an effective measure of deprivation [25]. In the UK the TID has been associated with various measures of health, including child obesity [27] and mortality through suicide [28]. However, there is no dimension of "environmental quality" in the TID although such measures of deprivation have often been explored in association with indicators of local environmental quality, especially factors such as air pollution and how this impacts on health [13,29,30]. A further criticism rests with its relative simplicity given that it has just four components, and two of them are related to "ownership" (home and car). The social dimension of sustainable development embraces far more than the four elements of the TID, but in that sense the index has much the same limitation as that of the HDI.

\section{Methodology}

The EF data for local authorities in England were obtained from the SEI website [24]. The precise terminology of "local authority" in England can be confusing as some are boroughs (e.g., in London and other cities), districts or unitary authorities, but here the units employed by SEI were used and these are referred to as "districts". The "local authorities" are grouped into geographical regions that do not necessarily have a governance role. Thus, the East Midlands region comprises 40 local authorities but there is no elected governance structure at the regional scale. London is the exception as the 33 boroughs (or districts) sit within a governance structure composed of an elected assembly and a mayor. While the regions, with the exception of London, are not administrative units they do broadly provide a basis for exploring geographical variation across the country.

Of the original EF components used by the SEI for their EF only 5 were employed in the analysis, namely housing, transport, food, consumer items and private services. The values for public services, capital investment and "other" were constant for all of the local authorities $(0.59,0.12$ and $0.01 \mathrm{gha} /$ capita respectively) and thus omitted from the analysis. These data were used to calculate an average EF and standard deviation for each of the regions in England; East, East Midlands, London, North East, North West, South East, South West, West Midlands and York and Humber. The EF data for the 5 components were used to calculate a 1st and 2nd Principal component.

The TID values for English local authorities were calculated from the 2001 census; the census that equates most closely with the time period for the EF data (2004 but published in 2008). Census data for that year were collected at parish scales in the UK (a local authority is comprised of a number of parishes) and the parish data were aggregated to produce a value for the local authorities that match those employed by SEI for the EF. Given that the four components of the TID have different units it was necessary to standardize them before taking the mean: 
Standardized value for each TID component $=($ value - mean $) /$ standard deviation

The higher the value of the TID then the greater the degree of deprivation.

A number of methods were employed for data analysis, but primarily these were principal component analysis (PCA) and least squares linear regression employed to relate TID with EF. PCA is a way of accounting for the variation in a dataset using a number of "principal components". The first PCA accounts for as much of the variability in the data as possible, and this is followed by the second, third etc. which in turn account for as much of the remaining variation as they can. In the results reported here only the first two principal components were included in the analysis.

In some cases comparisons were made using the Kruskal Wallis non-parametric test. This test checks whether two or more independent samples come from identical populations, and is thus a nonparametric alternative to a one-way ANOVA. The KW test is performed on ranks of the original data rather than the data themselves. Hence the smallest value gets a rank of 1 , the next smallest gets a rank of 2 and so on for the entire dataset (procedures are in place to accommodate tied ranks - usually by averaging). The test then compares the mean ranking of the categories (not the medians of the raw data in the categories) and calculates a statistic referred to as " $\mathrm{H}$ ".

\section{Results}

The averages and standard deviations of the 5 components of the EF for the 9 English regions are shown in Table 2. The results of a Kruskal Wallis non-parametric test on the EF components are also shown in Table 2. For the housing and transport components the highest footprints are for the South East region and in the case of housing it is lowest for the East Midlands. The transport footprint is also high for the East and South West. In the case of the food footprint the highest footprint is for London, but high values are also found for the South East and East. Lowest "food footprints" are found for the North East, West Midlands and York and Humber. The South East again comes top for the "consumer items" footprint while the lowest values are for the North East and North West. Finally, the "private services" footprint is highest for the South east and London. The overall pattern is indicative of higher footprints (greater impact from consumption/capita) towards the south and east of England and lower footprints towards the north.

Table 3 gives the average (and standard deviation in parentheses) of the TID for the 9 English regions. The values are the averages across the 4 standardized components of the TID and that is why some are negative. Higher values equate to higher deprivation. London is the region with the highest level of deprivation at the time the data were collected (2001 census). This might be surprising to the reader but to this day parts of London continue to have some of the highest deprivation in the whole of the UK. However, it should be noted that the components of the TID could potentially distort the picture for London given that it has a good public transport system and property prices tend to be higher than the rest of the country. Hence even households that are relatively wealthy may not need to own a car and may rent rather than own their accommodation. 
Table 2. Averages and standard deviations (parentheses) of the five components of the Stockholm Environment Institute's Ecological Footprint (EF) across the 9 English regions (gha/capita). The average EFs are based upon the sum of the 5 components and do not include public services, capital investment and "other" as these were identical for all regions. The table also shows the results of a Kruskal Wallis non-parametric test $(* * *=p<0.001)$.

\begin{tabular}{cccccccc}
\hline Region & Number of districts & Housing & Transport & Food & Consumer & Private & EF \\
\hline East & 48 & $1.30(0.07)$ & $1.08(0.08)$ & $1.37(0.08)$ & $0.75(0.04)$ & $0.31(0.02)$ & $4.81(0.26)$ \\
East Midlands & 39 & $1.27(0.05)$ & $0.97(0.08)$ & $1.34(0.07)$ & $0.72(0.04)$ & $0.28(0.01)$ & $4.58(0.24)$ \\
London & 33 & $1.32(0.08)$ & $0.94(0.15)$ & $1.44(0.18)$ & $0.74(0.09)$ & $0.36(0.05)$ & $4.80(0.53)$ \\
North East & 23 & $1.29(0.09)$ & $0.76(0.06)$ & $1.28(0.08)$ & $0.62(0.04)$ & $0.25(0.01)$ & $4.20(0.26)$ \\
North West & 40 & $1.30(0.07)$ & $0.91(0.08)$ & $1.36(0.1)$ & $0.70(0.05)$ & $0.29(0.02)$ & $4.55(0.30)$ \\
South East & 67 & $1.35(0.1)$ & $1.07(0.09)$ & $1.38(0.1)$ & $0.80(0.05)$ & $0.33(0.02)$ & $4.93(0.34)$ \\
South West & 45 & $1.32(0.08)$ & $1.03(0.05)$ & $1.32(0.05)$ & $0.75(0.03)$ & $0.30(0.01)$ & $4.73(0.19)$ \\
West Midlands & 34 & $1.29(0.07)$ & $0.92(0.09)$ & $1.28(0.09)$ & $0.69(0.05)$ & $0.28(0.02)$ & $4.46(0.30)$ \\
York and Humber & 23 & $1.34(0.09)$ & $0.93(0.08)$ & $1.28(0.08)$ & $0.69(0.04)$ & $0.28(0.02)$ & $4.52(0.29)$ \\
\hline H and significance & & $37.81 * * *$ & $170.35 * * *$ & $59.17 * * *$ & $173.24 * * *$ & $240.46 * * *$ & $102.38^{* * *}$ \\
\hline
\end{tabular}


It can be seen from Table 3 that the lowest levels of deprivation at the time of the census were in the South East, the South West and the East regions. It is also interesting to note the variation within each region. This was, again, highest for London, but the North East and York and Humber were not far behind. These are aggregated values for each region and it is instructive to look at how the mean TID was related to the standard deviation (SD) within each region. Plots of the mean TID against the SD for each region are shown in Figure 4. As perhaps would be expected, and for most regions, the SD increases as the mean increases, and this probably reflects a skewing within the data used to calculate the TID. This is not uncommon with data of this type, and suggests that at higher means of deprivation in an area there is also a greater degree of variation. However, it is interesting to note that the fitted regression lines for all regions have similar slopes, the exception perhaps being London (2.38) and at the other extreme the South West (0.45). The distribution of points around the "best fit" regression lines is also worth of note, especially for London. Greater London is very diverse in terms of its distribution of wealth, with affluent areas existing in close proximity to those with high deprivation.

Table 3. Mean and standard deviations for the Townsend Index of Deprivation (TID) of the 9 English regions. The table also shows the results of a Kruskal Wallis non-parametric test $(* * *=p<0.001)$.

\begin{tabular}{ccc}
\hline Region & Number of districts & Mean (SD) \\
\hline East & 48 & $-0.38(0.4)$ \\
East Midlands & 39 & $-0.29(0.43)$ \\
London & 33 & $0.88(0.64)$ \\
North East & 23 & $0.18(0.63)$ \\
North West & 40 & $-0.06(0.65)$ \\
South East & 67 & $-0.45(0.42)$ \\
South West & 45 & $-0.40(0.36)$ \\
West Midlands & 34 & $-0.25(0.53)$ \\
York and Humber & 23 & $-0.05(0.63)$ \\
\hline H and significance & & $111.2 * * *$ \\
\hline
\end{tabular}

Figure 5 is a plot of the 1st principal component of the EF against the 2nd Principal component. While the analysis was conducted on all of the EF data combined the regions have been separated out and best fit regression lines applied to each. Most of the regions are grouped within a relatively small space within the graph (suggesting a degree of homogeneity within the EF space defined by the 1st and 2nd PCs), but London in particular stands out as having a large spread in data points.

The separation is mostly in terms of the 2nd PC as seen in Figure 6 where the 1st and 2nd PCs are plotted against the EFs obtained by summing the 5 components. Please note that these EFs are not the ones published by the SEI as three components have not been included. The 1st PC from all the regions allow for a single best fit regression line, while for the 2 nd PC the groupings emerge. It seems as if the 1st PC captures a commonality amongst all the regions, while the second PC captures regional differences in footprint. In both cases higher values of the PC equate to higher EFs, and the greater spread in EF within London is especially apparent. 
Figure 4. Plots of mean TID against the standard deviation (SD) of the TID within each of the 9 English regions.

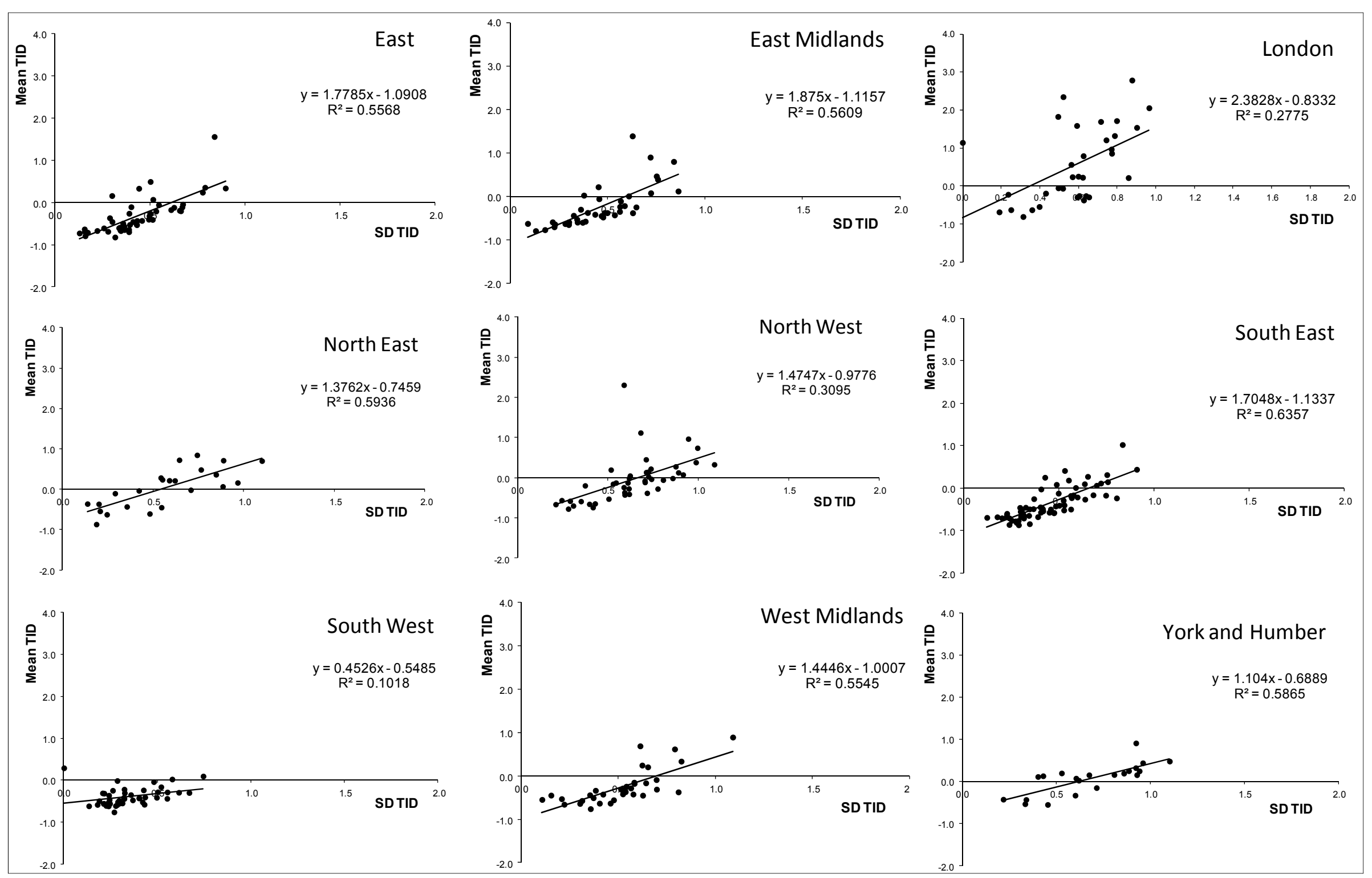


Figure 5. 1st Principal component plotted against the 2nd Principal Component of the EF data. The regions emerge as groupings within the graph and best-fit regression lines are shown for each of these.

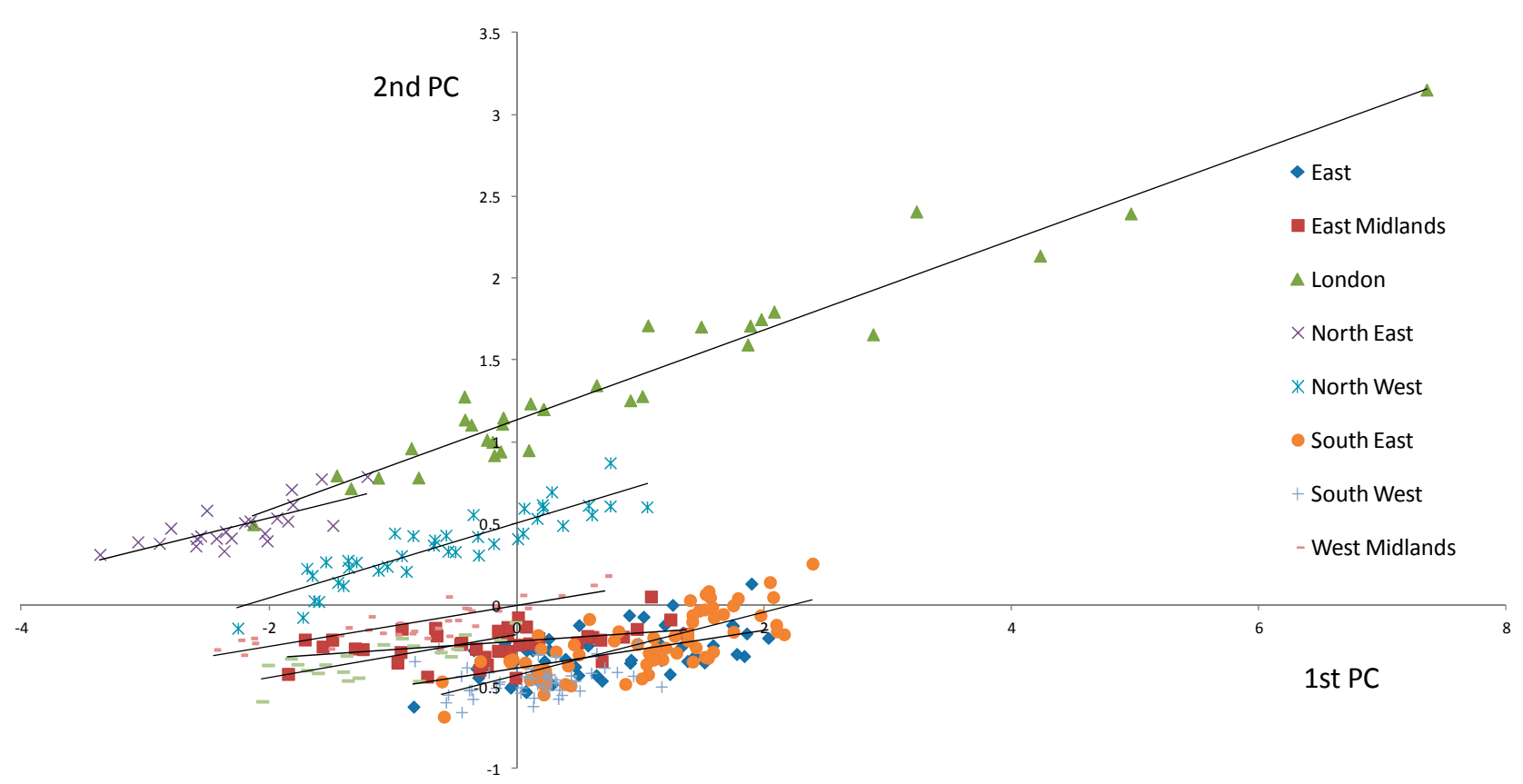

Figure 6. 1st and 2nd PCs plotted against the EF obtained by a simple summation of the EF components for all districts in the English regions.

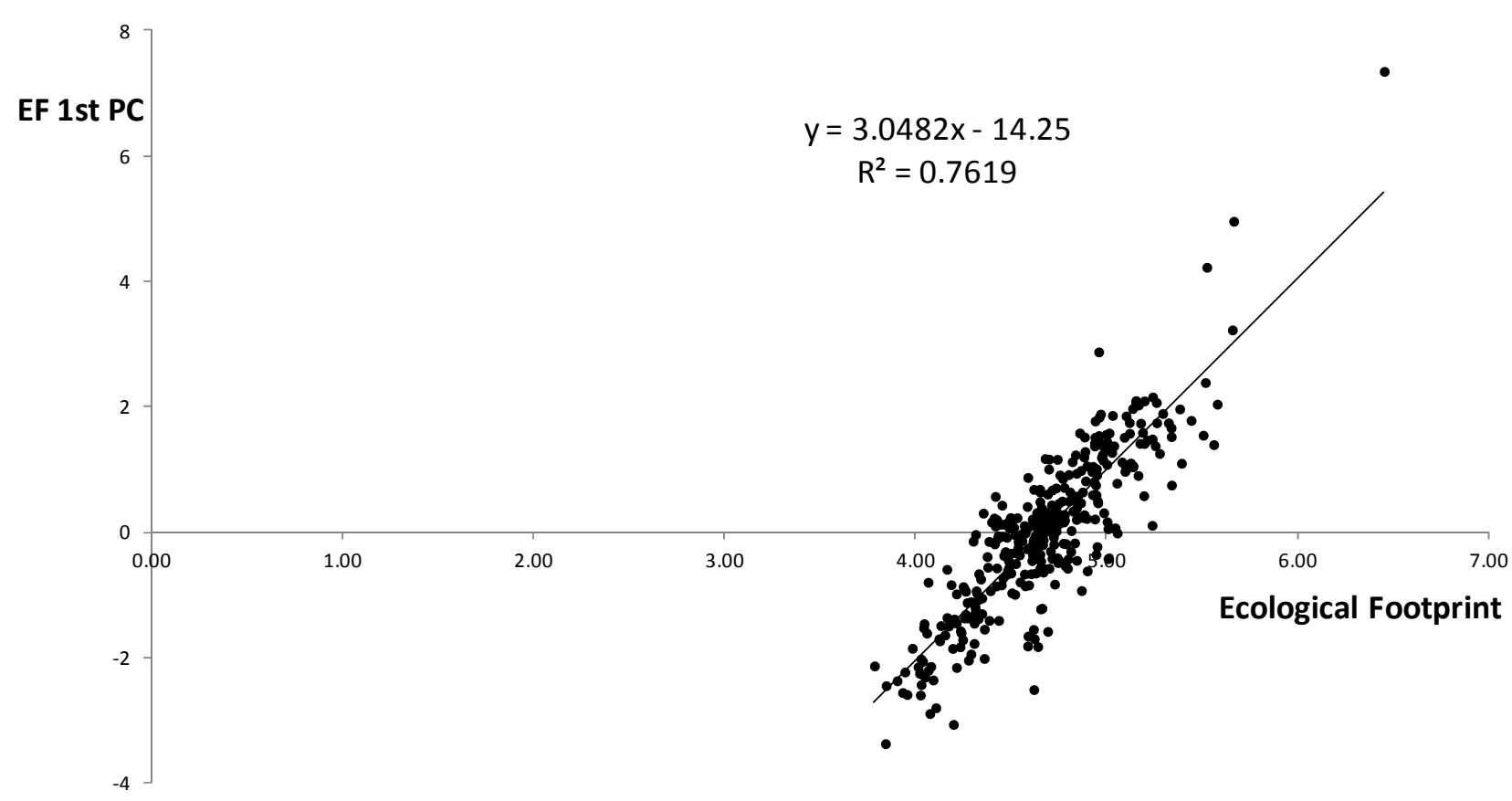


Figure 6. Cont.

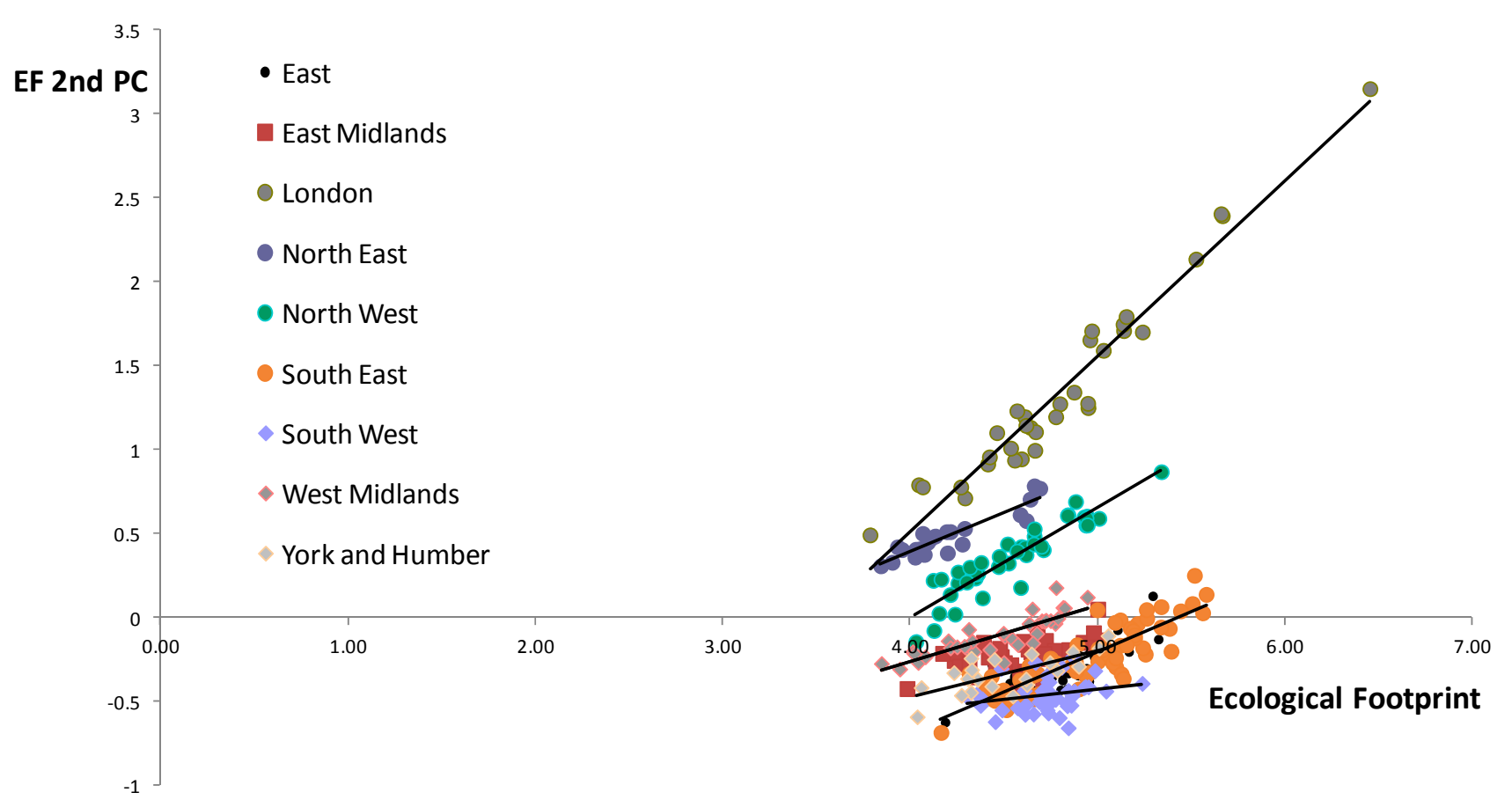

In terms of the relationship between the EF and the TID, Figures 7 and 8 are plots of the 1 st and 2nd PC respectively against the TID for the districts within each region. In Figure 7 there is a clear linear relationship between the two such that the EF increases as the level of deprivation declines. The pattern is the same across all regions, albeit with slightly different spreads and locations within the axes. The data for London are more spread than for the other regions. The data are remarkably consistent in terms of the location within the graphs and the slope of the fitted lines. London stands out as being quite different from the other regions and so indeed, but to a lesser extent, does the North East. The difference between London and the other regions is also noticeable in Figure 8 (2nd PC). With all the other regions the 2nd PC against TID generates small clusters of points in the graphs and these, again, are remarkably similar in terms of the size of the cluster and their placement within the two dimensional space. The difference seen with London in Figure 8 seems to stem from the large variation in TID between the London boroughs; this is much higher than the variation in EF for those boroughs.

The differences between London and the rest of the country are also apparent in Figures 9 and 10 . Both Figures 9 and 10 show the breakdown of the five components of the EF (their 1st PC) against the mean TID. In the case of Figure 9 the data are for all regions with the exception of London while Figure 10 presents the data just for London. In Figure 9 the clustering is very apparent, although it is interesting that while each of EF components has a similar relationship with TID the location of the cluster along the EF axis is different. For each of the components there is evidence of a linkage between EF and TID; as the TID increases then the EF declines. In Figure 10, where the data points are only for London, the locations of the clusters are similar to those in Figure 9 but the scattering of the points is very apparent, and is largely driven by the TID but also the spread of the EF component data, especially the food and transport components. The variation in the transport component could in part be a reflection of the extensive public transport system in London as an alternative to car use. 
Figure 7. Plots of mean TID against the 1st PC of the EF. Data are for districts within the English regions.

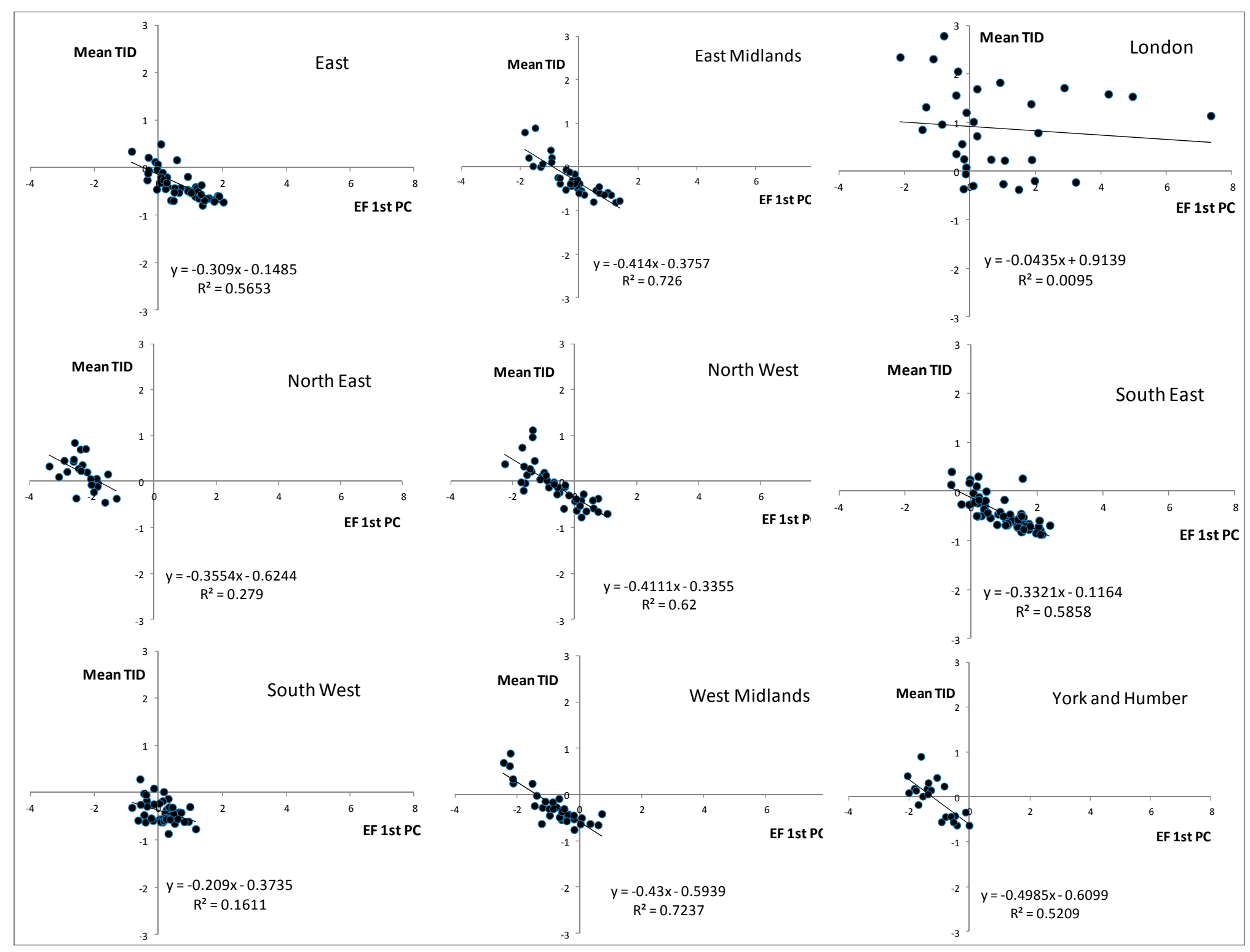


Figure 8. Plots of mean TID against the 2nd PC of the EF. Data are for districts within the English regions

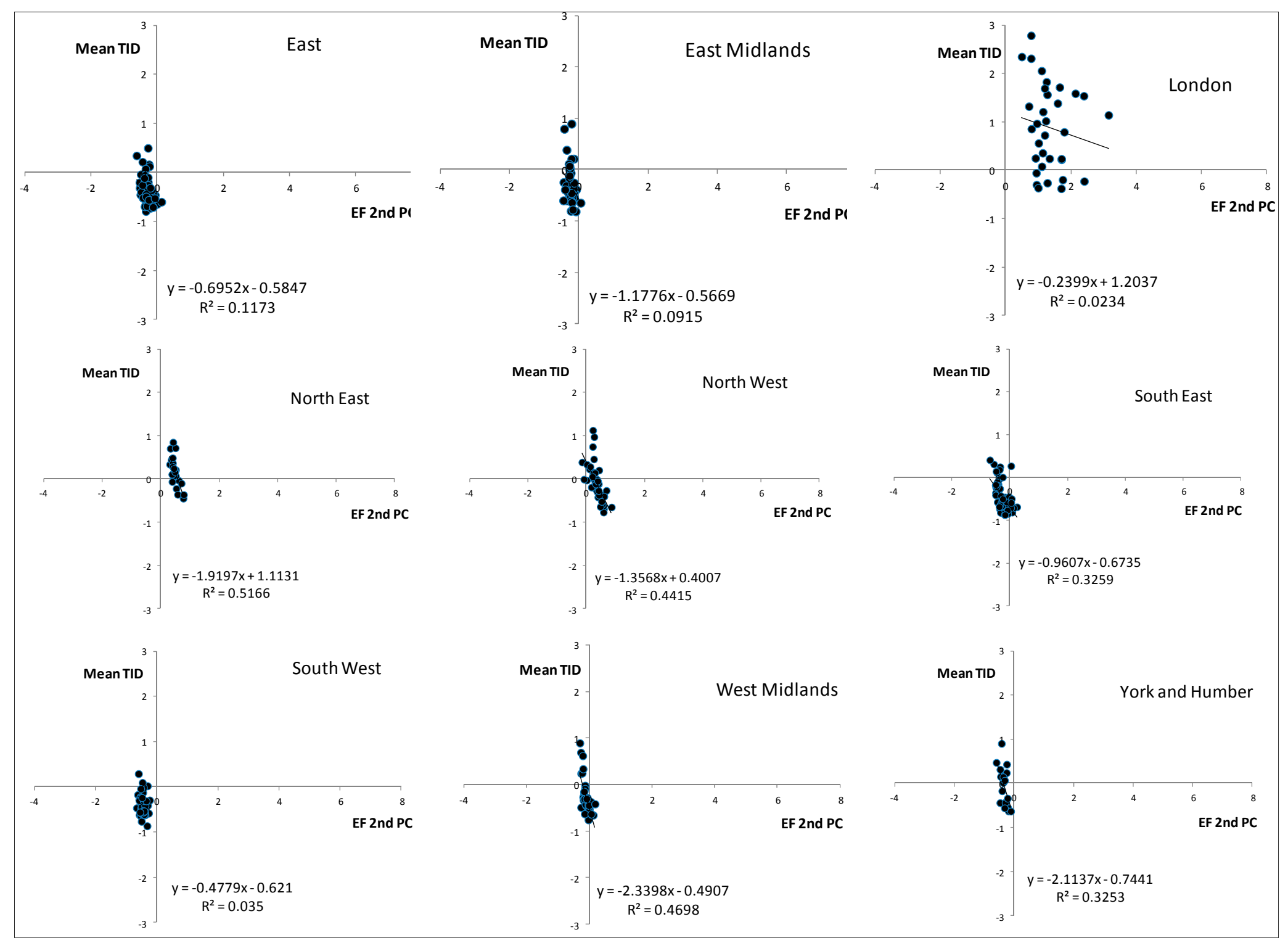


Figure 9. Mean TID as a function of the 1st PC of the components of the EF. Data are for all English regions except London and each dot represents a district.

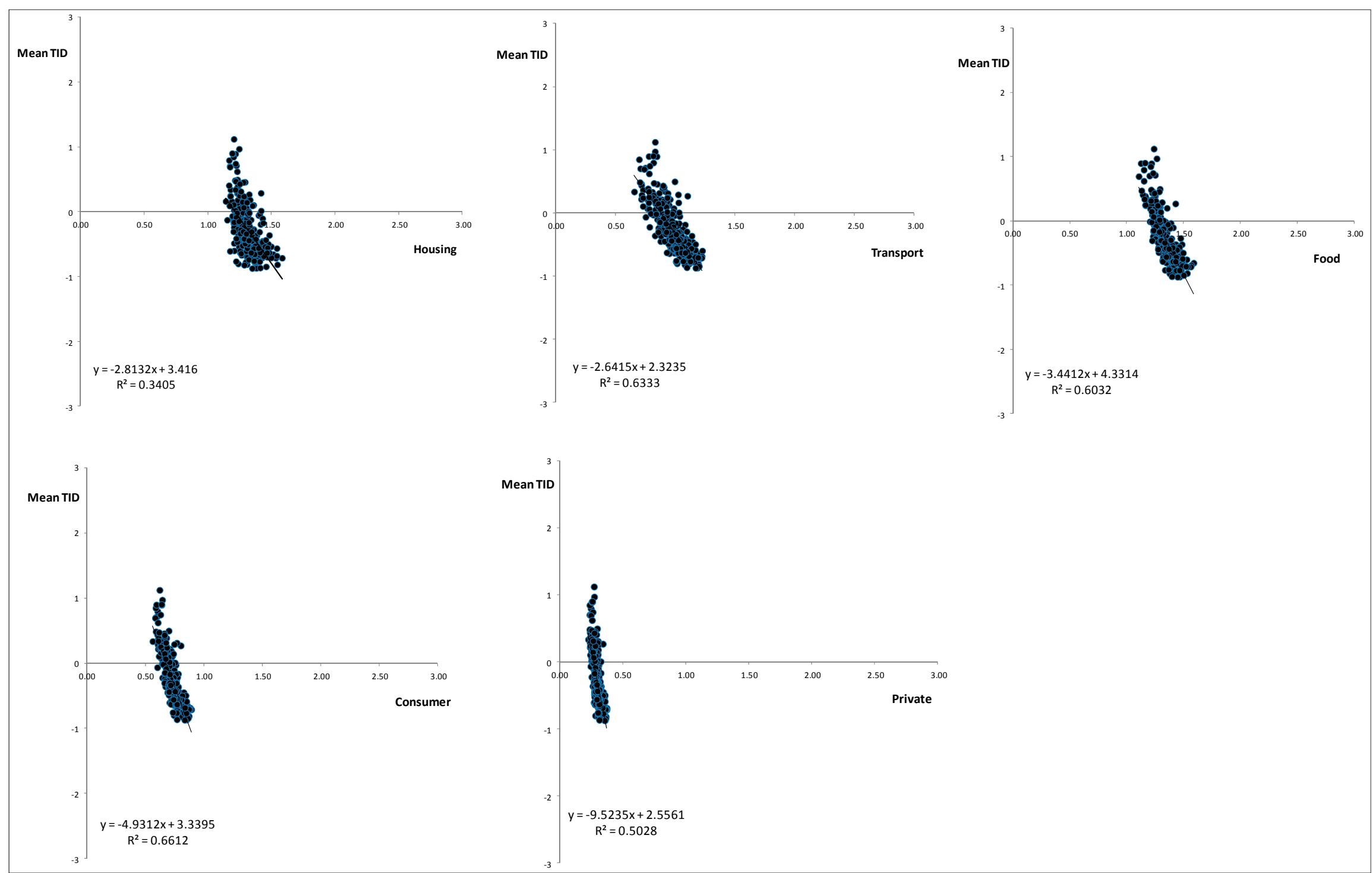


Figure 10. Mean TID as a function of the 1 st PC of the components of the EF. Data are only for Greater London and each dot represents a borough (district).

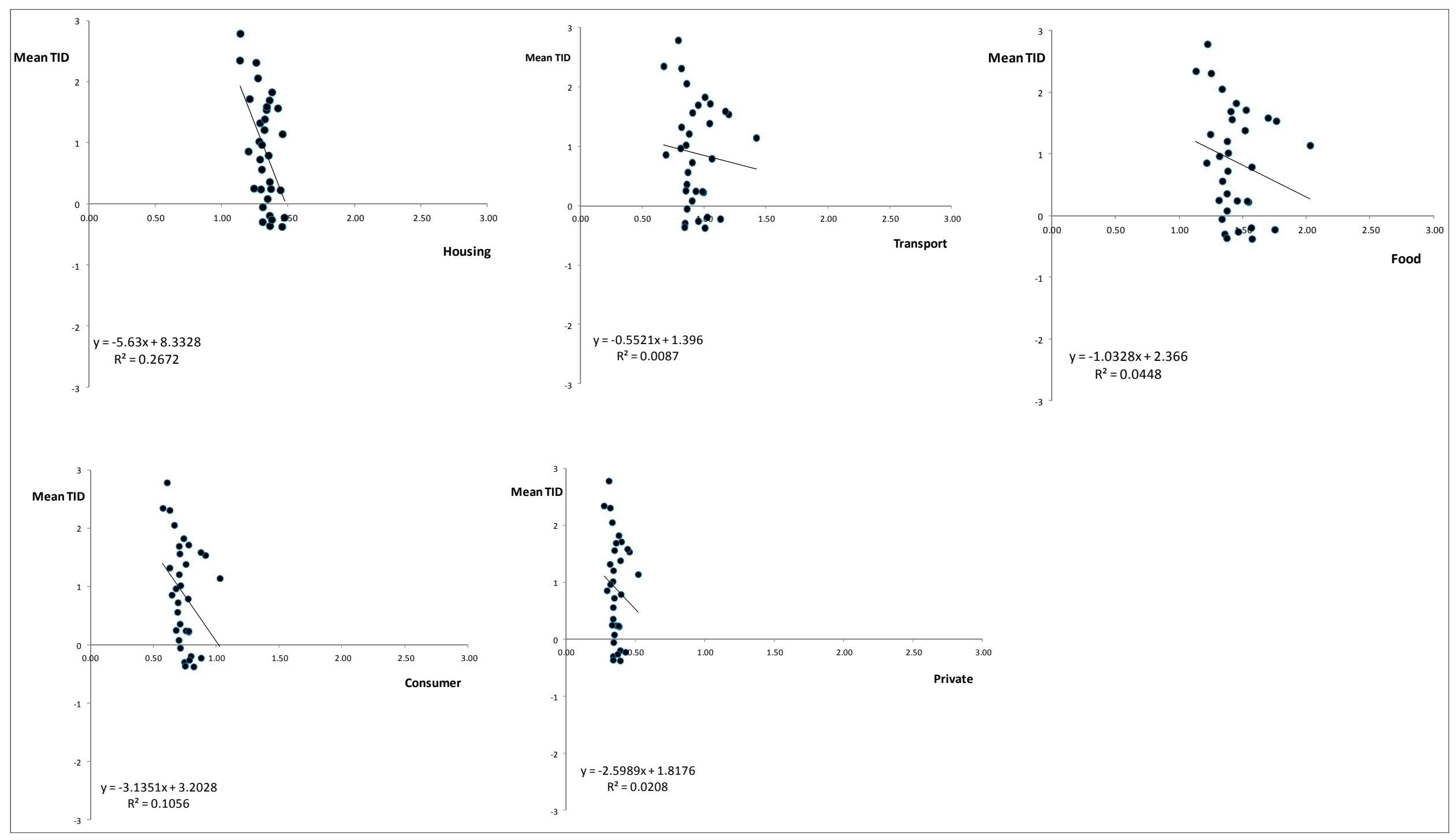




\section{Discussion}

This study is one of few using fine scale data to address the relationship between EF and TID at a national level. There are relatively few examples of such studies at the intra-country scale, probably due to a scarcity of good quality data. The results are in agreement with the Mitchell and Norman [13] and corroborate the relationship between affluence and EF in England. However, there is no diminishing return at the country level between TID and EF since most of the relationships in England and within the various geographical areas are markedly linear (with the exception of London). This contrasts with the plots between variables such as the HDI and EF which tend to show a leveling off at higher levels of the EF, although it is also worth noting that some of the leveling in the HDI-EF relationship could be due to a capping effect employed by UNDP in some of the HDI components. Such capping has not been employed here with the TID. The study has also demonstrated some key issues which have to be taken into consideration in similar type of analysis. On the one hand one would expect that EF would increase as a function of affluence. As households earn more, and this is proxied by the components of the TID even if income is not included as a component, then they are likely to purchase more of the items shown in Table 1. These are generalizations, of course, and no doubt much of the error seen in the various plots of TID and EF emerge from households that affluent but do not have a high EF to match and vice versa. However, despite the fact that various studies have demonstrated that affluence is directly related to their EF, this is not always straight forward, particularly when working at the household level. For example a study from Finland [31] working with low-income households came to the conclusion that although they had lower EFs than those of the average Finn their consumption levels were still not sustainable (i.e., deprivation coupled with overconsumption). The results of $\mathrm{Wu}$ and $\mathrm{Xu}$ [32] for the Heihe river basin, China, highlight a strong rural-urban dichotomy with regard to resource consumption, with urban areas having a greater degree of resource consumption. However, in the results presented here London does not seem to have an EF much greater than other regions and even within the city there is high variation.

So what is it about London that creates such a difference when compared with other regions of England? Why is it that the TID seems to be delinked from the EF? The variation in TID between the London boroughs is certainly much greater than seen for any of the districts within the other regions of England, but it is interesting to note that compared with non-London districts the level of deprivation for every London borough tended to be relatively high. While the boroughs are often seen as being quite different in terms of their wealth, with boroughs in the South West and West of the city seen as more affluent than those in the East and South East, but even within affluent boroughs there are areas of deprivation and the reverse is true for boroughs seen as less affluent. Hence one can readily imagine that the range of the TID for the London boroughs would be higher than for other regions. Why some of the EF components should also be so variable compared with other regions is less apparent. One explanation may rest with the structure of the TID and the inclusion of components focused on car and home ownership. Even relatively wealthy households in London may not see the need for a car given the good transport infrastructure and high property prices tend to mean that many households rent rather than own their accommodation. However, even with the larger ranges in the TID and EF for the hypothesis to be true one would expect to see a curved relationship yet this is not apparent in the data. 
An important issue is that the components within the TID and EF operate at various scales with different sensitivity across administrative scales. Tzanopoulos et al. [33] showed that direct drivers demonstrate higher sensitivity across administrative levels compared to indirect drivers, as they operate in a non-linear way. This is also the case with many of the components of the EF compared to those of the TID. Furthermore, policies and policy instruments influencing these components are elaborated over multiple administrative levels, which do not match the scales of measurement or reporting. The TID values have been calculated using the parish and then aggregated to districts and regions, while the EF data have been estimated at the district scale.

Future work should be able to identify tipping points i.e., pairs of values on the curve $\left(\mathrm{x}_{\mathrm{i}}, \mathrm{y}_{\mathrm{i}}\right)$ where the relationship between TID and EF is not sustainable for a given geographical area in the long run. Although the difficulties of the concept and its application in ecological systems have been discussed [34], conceptually there are certain analogies which could be taken into consideration in this study. These include the linear response of EF to TID, the multiple interactions between TID components and the fact that driver and response variables may operate at different time scales. There is also scope to look at other measures of deprivation, such as the Indices of Multiple Deprivation (IMD) which exist for England and see how they are linked to consumption. The IMD is far more complex than the TID and covers a number of dimensions rather than just the four in the TID. For example, the IMD developed for England and published in 2000 has 6 "domains" of deprivation and a total of 32 indicators. However the IMD needs more data than those available from the census and this does limit the spatial scales at which it is available. Nonetheless, the IMD is more favored by the UK government in terms of policy and this helps to offset some of its disadvantages as a research tool.

Finally it should be mentioned that this paper touches upon one of the most important elements of sustainable development - the decoupling of wealth and environment impact as expressed through models such as the Environmental Kuznets Curve. The relationships in all of the graphs presented in this paper between EF and TID do not show that such a decoupling has been reached, but a key assumption rests with the relationship between EF and negative environmental impact and as Fiala [22] has pointed out it is possible that innovation will come to the rescue and allow a decoupling between consumption and impact. In policy terms it is challenging to limit consumption, especially as people develop expectations for the sort of goods embodied in the TID. Is it possible to identify an optimal value for the TID in terms of what people can expect and balance that against an EF that the planet can sustain? To date there is no evidence which suggests it is possible to use the analysis shown in this paper to "manage" a society in this way even if it was thought to be desirable.

\section{Conclusions}

The results from this research suggest that the relationship between the EF and deprivation for most of the English regions is markedly linear; with the level of deprivation declining with increasing EF. This trend is probably as would be expected given that both EF and deprivation would be expected to be more homogeneous within a country than between the range of countries used to create Figures 2 and 3. Less deprivation in a district within a region would understandably be equated with more expenditure on the goods and services shown in Table 1 and hence increase the SEI version of the EF. However, the range in both EF and deprivation is not enough to generate the curves seen in Figures 2 
and 3. This is the case for all five of the components of the SEI version of the EF examined here, and the picture is remarkably consistent across most of the regions. The only region where this simple picture becomes distorted is London, and the reasons for this are unclear other than pointing to the wide variation in deprivation one can see in that city, even at very small spatial scales. In this region the variation in both EF and TID is greater than in the others, but the outcome is a move away from the clear linear relationship to an absence of any discernible trend.

\section{Acknowledgments}

The authors would like to thank two anonymous reviewers for their comments on a previous version of the manuscript.

\section{Author Contributions}

Stephen Morse designed the research, carried out the statistical analysis and drafted the manuscript. Ioannis Vogiatzakis collated the necessary datasets, carried out the pre-processing of spatial data, contributed to all versions of the manuscript and handled submission.

\section{Conflict of Interest}

The authors declare no conflict of interest.

\section{References}

1. Jackson, T. Prosperity without Growth: Economics for a Finite Planet; Earthscan: Abingdon, UK, 2009.

2. Wackernagel, M.; Rees, W.E. Our Ecological Footprint: Reducing Human Impact on the Earth; New Society Publishers: Gabriola Island, BC, Canada, 1996.

3. Holmberg, J.; Lundqvist, U.; Robert, K.H.; Wackernagel, M. The ecological footprint from a systems perspective of sustainability. Int. J. Sustain. Dev. World Ecol. 1999, 6, 17-33.

4. Ferguson, A.R.B. The assumptions underlying eco-footprinting. Popul. Environ. 2002, 23, 303-313.

5. Wackernagel, M.; Schulz, N.B.; Deumling, D.; Linares, A.C.; Jenkins, M.; Kapos, V.; Monfreda, C.; Loh, J.; Myers, N.; Norgaard, R.; et al. Tracking the ecological overshoot of the human economy. Proc. Natl. Acad. Sci. USA 2002, 99, 9266-9271.

6. Haberl, H.; Wackernagel, M.; Wrbka, T. Land use and sustainability indicators. An introduction. Land Use Policy 2004, 21, 193-198.

7. Haberl, H.; Wackernagel, M.; Krausmann, F.; Erb, K.H.; Monfreda, C. Ecological footprints and human appropriation of net primary production: A comparison. Land Use Policy 2004, 21, 279-288.

8. Kitzes, J.; Wackernagel, M. Answers to common questions in Ecological Footprint accounting. Ecol. Indic. 2009, 9, 812-817.

9. Larrea, M. Inequality, Sustainability and the Greed Line: A Conceptual and Empirical Approach. Ecum. Rev. 2011, 63, 263-277. 
10. Global Footprint Network. Available online: http://www.footprintnetwork.org/en/index.php/GFN (accessed on 18 May 2014).

11. World Wildlife Fund. Available online: http:// www.wwf.org.uk (accessed on 18 May 2014).

12. Morse, S. Greening the United Nations' Human Development Index? Sustain. Dev. 2003, 11, 183-198.

13. Mitchell, G.; Norman, P. Longitudinal environmental justice analysis: Co-evolution of environmental quality and deprivation in England, 1960-2007. Geoforum 2012, 43, 44-57.

14. Vanderheiden, S. Two conceptions of sustainability. Polit. Stud. 2008, 56, 435-455.

15. Van den Bergh, J.C.J.M.; Verbruggen, H. Spatial sustainability, trade and indicators: An evaluation of the 'ecological footprint'. Ecol. Econ. 1999, 29, 61-72.

16. Ayres, R.U. Commentary on the utility of the ecological footprint concept. Ecol. Econ. 2000, 32, 347-349.

17. Van Kooten, G.C.; Bulte, E.H. The ecological footprint: Useful science or politics? Ecol. Econ. 2000, 32, 385-389.

18. Van den Bergh, J.; Verbruggen, H. An evaluation of the 'ecological footprint': Reply to Wackernagel and Ferguson. Ecol. Econ. 2000, 31, 319-321.

19. Monfreda, C.; Wackernagel, M.; Deumling, D. Establishing national natural capital accounts based on detailed-Ecological Footprint and biological capacity assessments. Land Use Policy 2004, 21, 231-246.

20. Hammond, G.P. People, planet and prosperity: The determinants of humanity's environmental footprint. Nat. Resour. Forum 2006, 30, 27-36.

21. Kitzes, J.; Galli, A.; Bagliani, M.; Barrett, J.; Dige, G.; Ede, S.; Erb, K.; Giljum, S.; Haberl, H.; Hails, C.; et al. A research agenda for improving national Ecological Footprint accounts. Ecol. Econ. 2009, 68, 1991-2007.

22. Fiala, N. Measuring sustainability: Why the ecological footprint is bad economics and bad environmental science. Ecol. Econ. 2008, 67, 519-525.

23. Siche, J.R.; Agostinho, F.; Ortega, E.; Romeiro, A. Sustainability of nations by indices: Comparative study between environmental sustainability index, ecological footprint and the emergy performance indices. Ecol. Econ. 2008, 66, 628-637.

24. Resource Accounting. Available online: http://www.resource-accounting.org.uk/ (accessed on 18 May 2014).

25. Morris, R.; Carstairs, V. Which deprivation? A comparison of selected deprivation indexes. J. Public Health Med. 1991, 13, 318-326.

26. Townsend, P.; Phillimore, P.; Beattie, A. Health and Deprivation: Inequality and the North; Croom Helm: London, UK, 1988.

27. Kinra, S.; Nelder, R.P.; Lewendon, G.J. Deprivation and childhood obesity: A cross sectional study of 20,973 children in Plymouth, United Kingdom. J. Epidemiol. Community Health 2000, 54, 456-460.

28. Whitley, E.; Gunnell, D.; Doring, D.; Smith, G.D. Ecological study of social fragmentation, poverty and suicide. Br. Med. J. 1999, 319, 1034-1037.

29. Briggs, D.; Abellan, J.J.; Fecht, D. Environmental inequity in England: Small area associations between socio-economic status and environmental pollution. Soc. Sci. Med. 2008, 67, 1612-1629. 
30. Pearce, J.R.; Richardson, E.A.; Mitchell, R.J.; Shortt, N.K. Environmental justice and health: A study of multiple environmental deprivation and geographical inequalities in health in New Zealand. Soc. Sci. Med. 2011, 73, 410-420.

31. Lettenmeier, M.; Hirvilammi, T.; Laakso, S.; Lähteenoja, S.; Aalto, K. Material Footprint of Low-Income Households in Finland-Consequences for the Sustainability Debate. Sustainability 2012, 4, 1426-1447.

32. $\mathrm{Wu}, \mathrm{C}$; $\mathrm{Xu}, \mathrm{Z}$. Spatial distribution of the environmental resource consumption in the Heihe River Basin of Northwestern China. Reg. Environ. Change 2010, 10, 55-63.

33. Tzanopoulos, J.; Mouttet, R.; Letourneau, A.; Vogiatzakis, I.N.; Potts, S.G.; Henle, K.; Mathevet, R.; Marty, P. Scale sensitivity of environmental change across Europe. Glob. Environ. Change 2013, 23, 167-178.

34. Groffman, P.M.; Baron, J.S.; Blett, T.; Gold, A.J.; Goodman, I.; Gunderson, L.H.; Wiens, J. Ecological thresholds: The key to successful environmental management or an important concept with no practical application? Ecosystems 2006, 9, 1-13.

(C) 2014 by the authors; licensee MDPI, Basel, Switzerland. This article is an open access article distributed under the terms and conditions of the Creative Commons Attribution license (http://creativecommons.org/licenses/by/3.0/). 